\title{
Endothelin-1 Induces Expression of Connective Tissue Growth Factor in Bronchial Epithelial Cells
}

\author{
A. Dosanjh*
}

Adjunct faculty The Scripps Research Institute, San Diego, CA 92122, USA

\begin{abstract}
Endothelin-1 (ET-1) is a potent vaso and bronchoconstrictor. We have previously shown that in the presence of ET-1 bronchial epithelial cells migrate more slowly. Connective tissue growth factor (CTGF) is a cysteine rich secreted protein and regulates fibrosis. In addition, we have previously shown that CTGF is expressed in airway epithelial cells under the conditions of stress starvation. The aim of this study was to describe the effect of ET-1 on CTGF expression, using a lung epithelial-fibroblast co-culture system. Bronchial epithelial cells (BEC) were grown and stimulated with ET-1, $100 \mathrm{ng} / \mathrm{ml}$ of media, for 24 hours. At 0, 4 and 24 hours, total RNA was isolated. Reverse transcription PCR was performed and CTGF transcripts were semi-quantified. In addition, BEC were grown in co-culture, in the presence of human lung fibroblasts (FB). The same experiment was conducted for FB grown in the presence or absence of ET-1. Control cells were grown only in the basal media. At both time points, following exposure to ET-1, BEC expressed more CTGF as compared to control. Cells in co-culture with FB, expressed no CTGF at 4 hours, and detectable CTGF at 24 hours. CTGF was detected at all time points for FB in both control and stimulated cells. ET-1 induces expression of CTGF in BEC as compared to control. ET-1 may be an important regulator of CTGF expression in the airway. Lung fibroblasts may secrete epithelial cell regulatory factors, controlling the expression of CTGF in the presence of ET-1.
\end{abstract}

\section{INTRODUCTION}

The endothelins are a family of endothelium-derived peptides with a variety of biological activities, including potent vasoconstriction and bronchoconstriction [1-3]. Endothelin-1 (ET-1) is upregulated during tissue repair and pulmonary fibrosis, and we have previously shown that in the presence of ET-1 bronchial epithelial cells migrate more slowly, which could potentially inhibit epithelial repair in the airway [1]. We have also previously shown that connective tissue growth factor (CTGF) is produced by bronchial epithelial cells, which are key cells in airway repair and remodeling, and contribute to the development of abnormal subepithelial fibrosis [2]. The interaction between bronchial epithelial cells and lung fibroblasts is a crucial factor in the development of airway inflammation and lung fibrosis. The aim of this study was to describe the effect of ET-1 on CTGF at the level of transcription, as compared to control cells in a coculture system.

\section{MATERIALS AND METHODS}

\section{Cell Culture}

Bronchial epithelial cells (Beas2B and BET1A, ATCC) were grown to $90 \%$ confluence under standard growth conditions, for these commercially available cell lines. The media used was Small Airway Growth Media (SAGM, Clonetics,San Diego). The cells were grown at $37^{\circ} \mathrm{C}$, in $5 \% \mathrm{CO}_{2}$ under sterile conditions. BEC were also grown in co-culture in the presence of human lung fibroblasts (FB, Clonetics, San Diego), on six well filter inserts under sterile conditions.

*Address correspondence to this author at the Adjunct faculty The Scripps Research Institute, San Diego, CA 92122, USA; Tel: 858-442-6146;

E-mail: adosanjh@ucsd.edu
The cells were exposed to shared soluble solutions, but not in direct physical contact with each other. Lung FB were grown alone in six well plates, in the presence or absence of ET-1. The three cellular conditions consisted of BEC, FB and co-cultured BEC and FB.

ET-1 at $100 \mathrm{ng} / \mathrm{ml}$ of media was added to the media for 24 hours. At time points of 0, 4 and 24 hours, total RNA was isolated by previously described methods [2].

\section{Isolation of RNA and RT-PCR}

RT-PCR was performed and CTGF transcripts were semi-quantified and normalized by previously described methods [2]. Briefly, Total RNA was isolated by using RNA Stat60 (Tel-test, Friendswood, TX USA), according to the manufacturers' instructions. RNA was then quantified fluorimetrically, using Sybr Green II (Molecular Probes, Eugene, OR, USA).

The isolated RNA (1ug) was then reverse transcribed using a total $20 \mathrm{ul}$ reaction, as described previously. The PCR products were then separated on a $2 \%$ agarose gel. The isolated and anticipated product size was 300 basepairs. Sequencing analysis was completed by using the ABI PRISM377 DNA sequencer (Applied Biosystems, Foster City, CA, USA).

The same experiments were conducted for lung FB grown only in the presence or absence of ET-1. Control cells were grown only in basal media, without addition of ET-1. The results are expressed in a semi-quantitative manner, using a scale of $0-2(0,+,++)$. More intense bands are graded two, present, one and none, zero.

\section{RESULTS}

At 4 and 24 hours following exposure to ET-1, BEC expressed CTGF as detected by semi-quantitative PCR analy- 
sis. The score was ++ at both time points. Control cells expressed comparatively lower levels of CTGF at 24 hours $(+)$, and none at 4 hours. CTGF was detected at all time points for FB in both control and stimulated cells. The results are summarized in Table $\mathbf{1}$.

Table 1. The Semi-Quantitative Expression of CTGF mRNA Transcripts, in the Presence or Absence of Endothelin-1 is Summarized. Cells were Grown Separately or in Co-Culture on Six well Inserts

\begin{tabular}{|l|c|c|c|}
\hline & & $\mathbf{4} \mathbf{~ h r s}$ & $\mathbf{2 4} \mathbf{h r s}$ \\
\hline \hline BEC & & & \\
& + ET-1 & ++ & ++ \\
& - ET-1 & 0 & + \\
\hline FB & & & \\
& + ET-1 & ++ & ++ \\
& - ET-1 & ++ & ++ \\
\hline BEC & & & ++ \\
& & 0 & + \\
\hline
\end{tabular}

Expression is reported as 0-none detectable; + , detectable; ++ highly detectable. Abbreviations: $\mathrm{BEC}=$ bronchial epithelial cells; $\mathrm{FB}=$ lung fibroblasts; $\mathrm{ET}-1=$ endothelin-1.

Control epithelial cells in co-culture with FB, expressed no CTGF at 4 hours, and ++ detectable CTGF at 24 hours. The co-culture stimulated cells, expressed no CTGF at four hours, and detectable transcripts at 24 hours.

Overall, ET-1 increased the expression of CTGF transcripts in BEC. In the co-culture system there was a downregulation of CTGF transcriptional expression. When lung fibroblast secretory proteins are in contact with the BEC, there is no expression in BEC after four hours of exposure to ET-1. This effect does not require physical contact between the two cell types, since the two cell types were separated by filter inserts.

\section{DISCUSSION}

This study was conducted to determine the expression of CTGF mRNA transcripts in bronchial epithelial cells and lung fibroblasts, grown in co-culture or separately, in the presence of ET-1. We have previously shown that BEC produce CTGF under conditions of stress starvation. The results indicate for the first time on ET-1 induces expression of CTGF in BEC, as compared to controls and may be an important regulator of CTGF expression in the airway. Lung fibroblasts grown alone, expressed CTGF transcripts in the presence or absence of ET-1.

The attenuation of CTGF expression by BEC in coculture with $\mathrm{FB}$, indicates that lung fibroblasts may secrete regulatory factors that could control the expression of CTGF in the presence of ET-1. Based on these results, ET-1 induces expression over basal levels of CTGF mRNA as early as four hours, and the effect lasts at least until 24 hours. In contrast, when grown in co-culture with lung FB, the levels are attenuated at four hours. This study highlights the communicatory cellular regulation of CTGF in two key airway cell types.

Other studies have shown that the communication between BEC and lung FB determines the overall inflammatory response to injury in the airway $[4,5]$. The development of subepithelial fibrosis is a result of stimuli, such as mechanical stress and exposure to environmental agents [6].

ET-1 is a multi-functional endothelium derived peptide, and is a known potent vaso and bronchoconstrictor. ET-1 activates vascular smooth muscle cells and is an important mediator in chronic pulmonary diseases such as asthma and fibrosis. CTGF is a key factor in repair and remodeling of the airway, and this study indicates that in the presence of ET-1, a cellular response results in the release of CTGF [7].

Other previous studies have shown that ET-1 upregulates CTGF in neonatal cardiac myocytes. The authors showed that ET-1 caused an increase in CTGF expression, maximally within one hour, but it was sustained over 24 hours [8]. Another report using gene array analysis to study lung fibroblasts, showed that ET-1 induces a program of matrix synthesis in lung fibroblasts, and that ET-1 may play a key role in connective tissue deposition during wound repair and in pulmonary fibrosis [9]. In another study, the pro-fibrotic effects of ET-1 were further demonstrated. The authors used dermal fibroblasts and showed that ET-1 induced connective tissue growth factor (CTGF) at higher levels than TGFb-1. The effect of ET-1 was noted to be biphasic with a lower induction at three hours and a delayed second induction after five days. In this study the effect of ET-1 on CTGF transcripts was noted at both four and 24 hours [10].

ET-1 is markedly up-regulated during tissue repair and in the patients with a variety of fibrotic diseases and these results suggested that ET-1 may play a key role in lung remodeling [11]. Increased ET-1 levels have been demonstrated in the bronchial epithelium of asthma patients [12].

\section{CONCLUSIONS}

Based on this and other studies, ET-1 and CTGF are important therapeutic targets in the modulation of pulmonary fibrogenesis, and understanding the regulatory mechanisms of the effect of ET-1 on lung fibrogenesis is an area of future research.

\section{ACKNOWLEDGEMENTS}

The author would like to thank Dr. Bruce Zuraw for providing TSRI laboratory space and support. Funding provided by the NIH.

\section{REFERENCES}

[1] Dosanjh A. Connective tissue growth factor expression in human bronchial epithelial cells. Acta Biochim Biophys Sin 2006; 38(1): 53-7.

[2] Dosanjh A, Zuraw B. Endothelin-1 (ET-1) decreases human bronchial epithelial cell migration and proliferation: implications for airway remodeling in asthma. J Asthma 2003; 40(8): 883-6.

[3] Busch T, Petersen B, Deja M, et al. Endothelin-1 influences the efficacy of inhaled nitric oxide in experimental acute lung injury. Exp Biol Med 2003; 231(6): 974-8.

[4] Holgate ST. The bronchial epithelial origins of asthma. Chem Immunol 2000; 78: 62-71. 
[5] Davies DE, Wicks J, Powell RM, et al. Airway remodeling in asthma: new insights. J Allergy Clin Immunol 2003; 111(2): 21525.

[6] Tschumperlin DJ, Shively JD, Kikuchi T, et al. Mechanical stress triggers selective release of fibrotic mediators from bronchial epithelium. Am J Respir Cell Mol Biol 2003; 28(2): 142-9.

[7] Rodriguez Vita J, Ruiz Ortega M, Ruperez M, et al. Endothelin-1, via ETA receptor and independently of transforming growth factorbeta, increases the connective tissue growth factor in vascular smooth muscle cells. Circ Res 2005; 97(2): 125-34.

[8] Kemp TJ, Aggeli IK, Sugden PH, et al. Phenylephrine and endothelin-1 upregulate connective tissue growth factor in neonatal rat cardiac myocytes. J Mol Cell Cardiol 2004; 37(2): 603-6.
[9] Xu SW, Howat SL, Renzoni EA, et al. Endothelin-1 induces expression of matrix-associated genes in lung fibroblasts through MEK/ERK. J Biol Chem 2004; 279(22): 23098-103.

[10] Horstmeyer A, Licht C, Scherr G, et al. Signalling and regulation of collagen I synthesis by ET-1 and TGF-beta1. FEBS J 2005; 272(24): 6297-309.

[11] Shao R, Shi Z, Gotwals PJ, et al. Cell and molecular regulation of endothelin-1 production during hepatic wound healing. Mol Biol Cell 2003; 14(6): 2327-41.

[12] Trakada G, Tsourapis S, Marangos M, et al. Arterial and bronchoalveolar lavage fluid endothelin-1 concentration in asthma. Respir Med 2000; 94(10): 992-6.

(C) A. Dosanjh; Licensee Bentham Open.

This is an open access article licensed under the terms of the Creative Commons Attribution Non-Commercial License (http://creativecommons.org/licenses/by-nc/3.0/) which permits unrestricted, non-commercial use, distribution and reproduction in any medium, provided the work is properly cited. 